\title{
Early evidence that social distancing and publichealth interventions flatten the COVID-19 curve in Italy
}

\author{
Authors: Valentina Rotondi, ${ }^{1 *}$ Liliana Andriano, ${ }^{1}$ Jennifer Beam Dowd, ${ }^{1}$ \\ Melinda C. Mills ${ }^{1}$
}

Affiliations: ${ }^{1}$ Leverhulme Centre for Demographic Science, University of Oxford \& Nuffield College, UK.

Current address: 42 Park End St, Oxford OX1 1JD, United Kingdom

${ }^{*}$ Correspondence to: valentina.rotondi@sociology.ox.ac.uk

\begin{abstract}
Abstract: With the world experiencing one of the largest pandemics in one-hundred years, governments and policymakers are looking for scientific evidence to introduce rapid and effective policies. Here we provide evidence from two provinces in Italy with comparable early infection rates but different timing of mitigating policy measures.

Lodi prohibited movement on February 23, 2020 and Bergamo 2 weeks later on March 8, before the entire lockdown of Italy on March 11. This comparison provides early evidence that rapid restriction of movement and social distancing measures may slow the transmission of the virus and "flatten the curve", ultimately reducing pressure on health care systems
\end{abstract}

Author contributions: VR, LA and MCM drafted the initial text and all authors revised and approved the final manuscript. VR and LA produced the graphics and Italian language media analysis and MCM the timeline.

Acknowledgments: Authors would like thank Leverhulme Centre for Demographic Science (LCDS) COVID-19 working group \& Kayla Schulte for graphics assistance.

Funding: The Leverhulme Trust (LCDS) and ERC (835079, MCM). Competing interests: The authors declare no conflict of interest. 


\section{Introduction}

In 1918, the Spanish flu pandemic resulted in an estimated 50-100 million deaths worldwide.(1) Two cities in the United States - Philadelphia and St. Louis - enacted very different policy responses.(2) Despite persistent warnings that the Spanish flu had begun to spread amongst soldiers preparing to leave for World War I, Philadelphia threw a large parade to boost morale, attended by 200,000 people. Conversely, when initial cases were detected in St. Louis, the city acted swiftly and resolutely introduced isolation of sick persons, closed public buildings, shut down schools, churches, courtrooms, libraries, banned gatherings, introduced staggered work shifts and limited public transportation.

The result of this disparate policy response of two cities was astonishing. Just days after the parade in Philadelphia, hospitals were flooded with patients suffering and dying from the Spanish flu. In fact, just a few weeks later, over 4,500 people in Philadelphia alone had died from the virus. St. Louis experienced 347 deaths per 100,000 - less than half the rate of Philadelphia. Across the US, cities that sanctioned extensive and early interventions had a median peak death rate of 65-69/10,00o whereas those who were late or engaged in no interventions had peaks of 127-146/10,00o.(2) Now, just over one-hundred years later and in the grips of a new pandemic, we are hoping that history does not repeat itself. Governments are looking for scientific evidence of public health interventions that will be effective to limit the transmission and ultimately deaths from COVID-19. Here we compare the growth of COVID-19 cases in two Italian provinces with similar early rates but different timing of the "lockdown." Lodi instituted lockdown on February $23^{\text {rd }}$, two weeks prior to Bergamo. We find evidence that the growth of cases was slower in Lodi compared to Bergamo, providing preliminary evidence of lockdown restrictions "flattening the curve" in Lodi. "Flattening the curve" refers to mitigation measures enacted during an epidemic to spread out the timing and peak of cases to avoid overtaxing of health care capacity and reduce total deaths. (3)

\section{Italy: A Tale of Two Provinces}

On Friday the $21^{\text {st }}$ of February2020, the first case of COVID-19 in Italy was confirmed in a man living in the town of Codogno in the province of Lodi, which is located in the Northern region of Lombardy in Italy (see Supp Info). The virus then 
spread across neighbouring regions in Northern Italy - including Veneto, Emilia Romagna, and Piedmont, all of whom began to report rapid increases in cases. Starting February $24^{\text {th }}$, the number of cases and deaths began to increase (for a timeline see Supp Info Fig S1).

The response of the Italian government to the spread of COVID-19 across Italy was aggressive, but was introduced across different regions in diverse ways, with varying levels of effectiveness. On February $23^{r d}$, the government issued a decree in 10 municipalities within the province of Lodi , in Lombardy, and a municipality located in the province of Padova, Vo', in Veneto (so-called "Red Zones"). The decree imposed the shutdown of firms within the Red Zones, prohibited the movement of people outside the lockdown municipalities, and closed public transportation from, to, and within the red zones. Within hours of the decree, the Veneto and Lombardy regions issued an ordinance that closed all schools and universities, and shut down all cultural, recreational, sporting and religious events, both public and private across all regional territories. Other regions in Northern Italy closed down schools and universities in the same day. This meant that in all other municipalities that were not included in the Red Zones, the movement of people continued, public transportation ran, and firms remained open.

Although cases in the province of Bergamo began to increase at an alarming rate, in contrast to Lodi, no further shutdowns or restrictions were imposed for another 2 weeks apart from school closures and limits to gatherings. On March $8^{\text {th }}$, however, the shutdown previously implemented in the 10 municipalities in the province of Lodi was partially expanded to the entirety of Lombardy (including Bergamo) and extended to fourteen provinces in Veneto, Emilia Romagna, Piedmont, and Marche. Starting from this date, people could no longer leave or enter Lombardy and the fourteen provinces and could only leave their homes for valid reasons. To do so, they had to provide a written certificate including the reason for their movements, which had to be related to work, medical reasons or obtaining food. Firms and public transportation remained open but were partially reduced. The decree, however, was leaked in the late evening of March $7^{\text {th }}$, generating a massive outflow of people from these regions in the North to several regions in the South, which at that time had few cases. Only two days later, a new decree of the Prime Minister Giuseppe Conte, extended these lockdown measures across the entire country of Italy until at least April $3^{\text {rd }}$. On March $11^{\text {th }}$, a further crackdown resulted in the closure of all shops (with the exception of groceries and pharmacies), pubs, and restaurants. On March $22^{\text {nd }}$, a new decree was issued that closed every non-necessary firm, restricted outdoor activities to areas only in the proximity of the home, increased fines for moving without valid reason, and prohibited movement outside municipality of residence.

As of March $23^{r d}$, the number of cases that tested positive for COVID-19 in Italy 
amounted to 50,418 , the number of deaths a staggering 6,077 and the number of recovered cases at 7,432 . With 18,910 (i.e., $37.5 \%$ of the total) cases tested positive for COVID-19, 3,776 deaths (i.e., 62.1\% of the total), and 6,075 recovered, Lombardy is the most affected region in Italy. Fig 1 illustrates the number of cases in Italy (left panel) and Lombardy (right panel) as of March $23^{r d}$ by province. Here we see that cases are concentrated in the province of Bergamo.
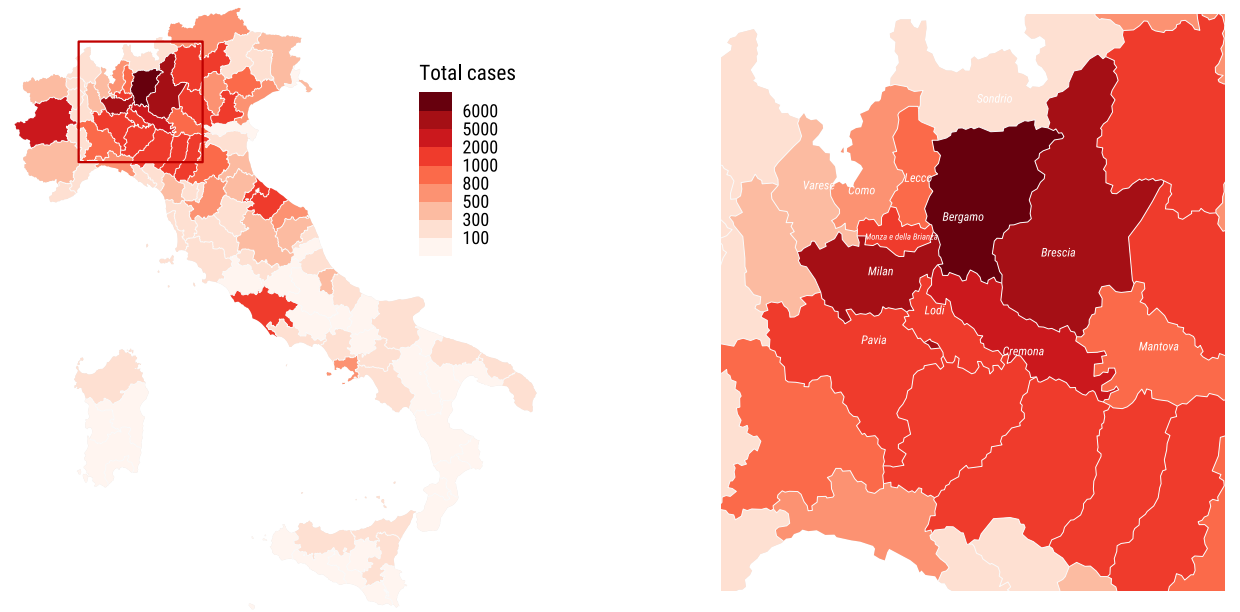

1. Map of number of COVID-19 cases by province, country of Italy (left panel) and Lombardy region (right panel) as of March 23, 2020. Note:

Darker colors indicate a larger number of cases, as reported in the legend. For source of data, see Data, Supp. Info.

As of March $13^{\text {th }}$, the most affected province of Bergamo (then at 2,368 cases) overtook the province of Lodi (then at 1,133 cases) where the outbreak started and the containment measures were rapidly employed, with the growth illustrated in Fig 2. This figure provides initial empirical evidence that the public health and social distancing interventions implemented two weeks earlier in Lodi compared to Bergamo may have helped 'flatten the curve' and slow the transmission of COVID-19.

We acknowledge that direct comparisons between different geographic locations is challenging, also since Lodi has a smaller population size of 230,198 compared to Bergamo with just over one million (1,114,590). Despite differences in population size between the two provinces, we considered absolute case numbers to be the best metric, since the initial clusters of infection outbreak within the two provinces occurred in a smaller number of municipalities with comparable population sizes (see Supp Info, Fig S2-S3).(4) At an early stage of the infection spread, standardizing by overall 
population size risks obscuring important dynamics that occurred in a smaller subset of municipalities.(4) We also engaged in additional sensitivity analyses with comparisons adjusted for population size (see Supp Info Fig S4-S5). Although more ideal, unfortunately detailed information about the daily increase in the number of cases or deaths at the municipality level is not publicly available at the time of writing. While we believe that the Lodi/Bergamo example is illustrative of the potential effectiveness of early interventions in slowing the epidemic, we acknowledge that limitations exist when analyzing real-time data during the midst of the outbreak. Other factors may have differed across provinces, such as the intensity of initial transmission chains and testing coverage in each province and available data does not allow us to rigorously test for causality. Due to low testing coverage and asymptomatic cases, the true number of COVID-19 cases remains unknown. A recent Science article suggested that the number of reported cases is merely tip of the iceberg (5). Future population serology and COVID-19 surveillance will help to provide evidence on the proportion of populations exposed to provide a more accurate picture of how this epidemic unfolded.

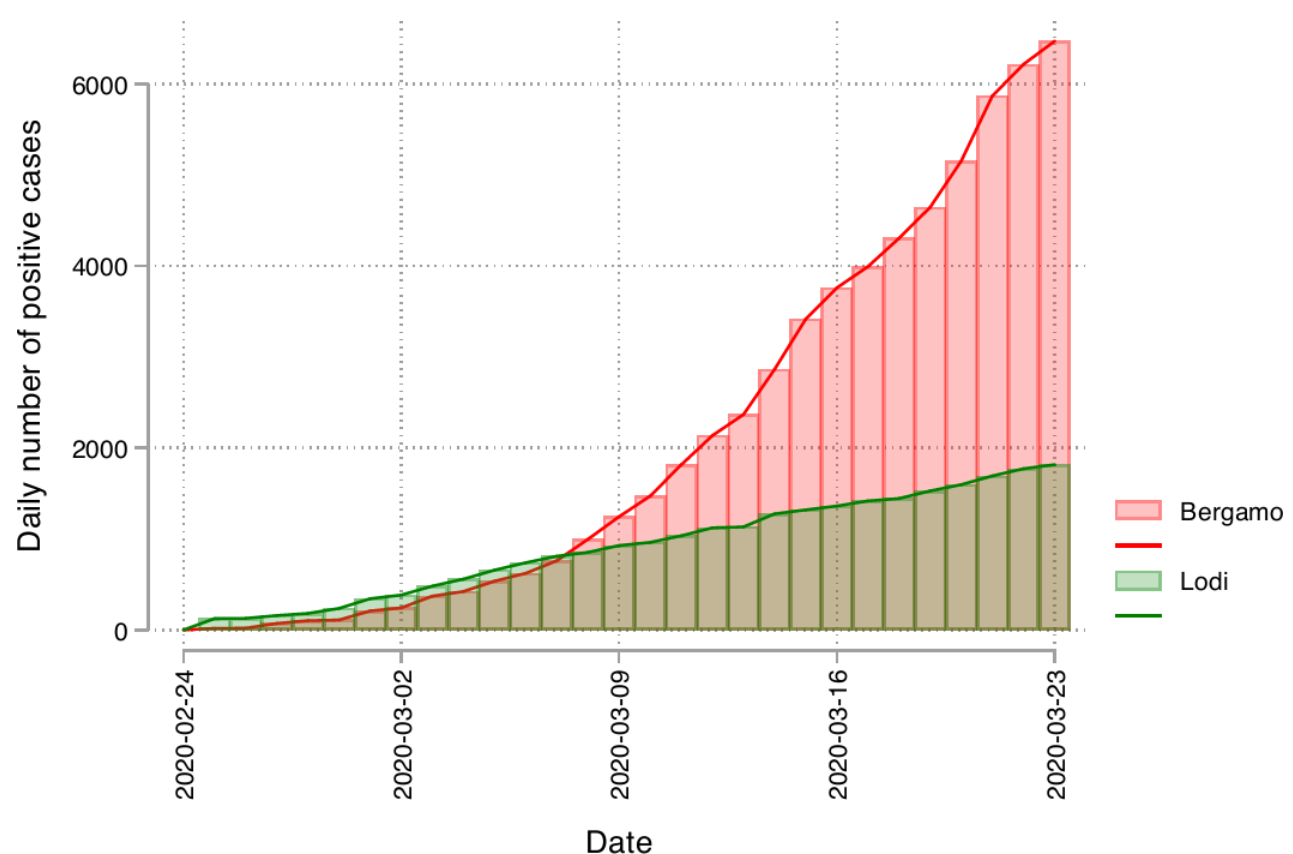

2. Flattening the curve through public health interventions: Number of cases in the Province of Bergamo (red) and Lodi (green) February 24 to March 22, 2020. Note: The figure shows the daily number of cases for Lodi (green) and Bergamo (red) by day.

\section{Moving forward with COVID-19 public health interventions}


for rapid public health interventions to slow the spread of a pandemic. These two provinces in Italy introduced public health and social distancing restrictions two weeks apart from one another. Although the lesson appears clear, we also note that Italy is a distinct case that may not necessarily generalize to other contexts. (6) Although it has a population of 60.4 million, by late March Italy sadly had more deaths from COVID-19 than large countries such as China, with a population of 1.4 billion.(7) It will take time to understand why the burden of COVID-19 mortality has been so high in Italy, which is also likely related to Italy's ageing population who suffer from higher COVID-19 fatality rates.(8) Differences in the stringency of public health measures, enforcement and compliance of measures by the population likely differ widely across regions and countries. Italy is also a country characterized by extensive intergenerational contacts, including higher co-residence but also high geographical proximity of family and regular meetings and eating together.(9) This high degree of intergenerational interaction might have played a role in the more rapid transmission, since younger individuals have been noted to be asymptomatic and thus can easily transmit without their knowledge.(10) Since deaths have been primarily concentrated in older individuals with pre-existing comorbidities, governments are increasingly adopting measures aimed at explicitly protecting interaction with the elderly and limiting visits. We encourage the timely release of both national and local data on COVID-19 cases and mortality in countries around the world to provide further opportunities to understand the factors that increase or mitigate transmission and the risk of mortality. 


\section{References}

1. A. Crosby, America's Forgotten Pandemic: The Influenza of 1918 (Cambridge University Press, Cambridge, ed. 2nd, 2003).

2. R. J. Hatchett, C. E. Mecher, M. Lipsitch, Public health interventions and epidemic intensity during the 1918 influenza pandemic. Proc. Natl. Acad. Sci. 104, 7582-7587 (2007).

3. S. Roberts, Flattening the Cornavirus Curve. New York Times (2020), (available at https://www.nytimes.com/2020/03/11/science/coronavirus-curve-mitigatio n-infection.html).

4. C. D et al., The early phase of the COVID-19 outbreak in Lombardy, Italy. arXiv (2020) (available at http://arxiv.org/abs/2003.09320).

5. R. Li et al., Substantial undocumented infection facilitates the rapid dissemination of novel coronavirus (SARS-CoV2). Science (80-. )., eabb3221 (2020).

6. J. B. Dowd, et al., Demographic science aids in understanding the spread and fatality rates of COVID-19. medRxiv (2020), doi:10.1101/2020.03.15.20036293.

7. E. Dong, H. Du, L. Gardner, An interactive web-based dashboard to track COVID-19 in real time. Lancet Infect. Dis. (2020), doi:10.1016/S1473-3099(20)30120-1.

8. Z. Wu, J. M. McGoogan, Characteristics of and Important Lessons From the Coronavirus Disease 2019 (COVID-19) Outbreak in China. JAMA (2020), doi:10.1001/jama.2020.2648.

9. M. Kalmijn, C. Saraceno, A Comparative Perspective on Intergenerational Support. Eur. Soc. 10, 479-508 (2008).

Data and materials availability: All data is available in the main text or the supplementary materials. Data for cases in Italy province from: https:/ /github.com/pcm-dpc/COVID-19/tree/master/dati-province 


\section{SUPPLEMENTARY INFORMATION}

\section{Materials and Methods}

\section{$\underline{\text { Materials }}$}

All data used to produce these graphics is publicly available on the website COVID-19 ItaliaMonitoraggio Situazione at: https://github.com/pcm-dpc/COVID-19

Figure 1, 2, S1, S4, and S5 use daily updated number of cases at the province level, accessed March 24, 2020. In this description, we refer to regions as the units (NUTS 2) in which Italy is divided and provinces as the units in which the regions are divided (NUTS 3).

\section{Methods}

Data analysis is conducted in R using the packages ggplot2, and in Stata using package twoway graph. Figures S2 and S3 have been processed in QGIS.

\section{Supplementary Text}

\section{Background on Lodi and Lombardy}

In this article, we focus in particular on one region, Lombardy, and two provinces within this region: the province of Bergamo and Lodi (BG and LO, respectively in Figure S3). The province of Lodi borders to the north the province of Milan while the province of Bergamo borders the province of Milan to the west.

According to Eurostat, Lombardy is the most populated region in Italy, among the wealthier regions in Europe, and the wealthiest in Italy, with a GDP per capita amounting to $€ 38,430$ in 2017 (compared to $€ 28,690$ in Italy and $€ 30,070$ in the EU).(1) With an unemployment rate of $6 \%$ in 2018, Lombardy ranks far below the Italian and European average $(10.6 \%$ and $6.9 \%$, respectively). Lombardy's economy is mainly dominated by small and medium sized enterprises, often family owned. The province of Milan dominates with nearly $40 \%$ of the total firms of the region. Milan also hosts the Italian Stock Exchange while the Milan Fair is the largest exhibition space in Europe. 
The timeline of lockdown measures in Italy

A timeline of the public health and government interventions along with the number of cases in the province of Lodi, Bergamo, and Italy is shown in Figure S1. As noted in the main text, on February 21 2020, the first case of COVID-19 was discovered in Codogno in the province of Lodi in the Lombardy region, in Northern Italy. Two days later, on February 23, the government issued a decree to create 'Red Zones', which prohibited the movement of people outside some municipalities of all areas indicated in orange in Figure S2. These were located in the region of Lombardy, within the province of Lodi (Codogno, Castiglione d'Adda, Casale, San Fiorano, Bertonico, Fombio, Terranova dei Passerini, Somaglia, Maleo and Castelgerundo) and a municipality in the region of Veneto, within the province of Padova (Vo' Euganeo). However, the decree was not implemented immediately. Implementation did not start rigidly, and checkpoints were not very effective: in fact, there were numerous leaks towards other provinces and regions in southern Italy.(3) Law enforcement officers (at least 500 officers) were deployed two days later in order to avoid further leaks. Simultaneously, cases also started to emerge in the province of Bergamo, particularly in the municipalities of Albino, Alzano, Nembro, and Zogno (in yellow in Figure S4).(4)

On the same day, the Veneto and Lombardy regions (as well as other regions in Northern Italy), issued an ordinance by which all schools of all levels and grades, including universities, were closed and all cultural, recreational, sporting and religious events, public or private, suspended. Throughout Italy all educational trips were also suspended, both for destinations in Italy and abroad. From March $4^{\text {th }}$, all schools closed across the entire country.

Starting on February $25^{\text {th }}$, press rumors continued to report the need to lockdown municipalities within the province of Bergamo since the number of infected cases and the deaths continued to increase at an alarming pace.(1) Those municipalities, however, did not close until the entire region of Lombardy was locked down on March $8^{\text {th }}$, see the main text and Figure S1 for a description of the decree, and Figure $\mathrm{S}_{3}$ for a graphical description of the provinces that were locked down. On March $10^{\text {th }}$, a new decree of the Prime Minister Giuseppe Conte, extended these lockdown measures across the entire country of Italy until at least April 3rd. On March 11th, a further crackdown resulted in the closure of all shops (with the exception of groceries and 
pharmacies), pubs, and restaurants. With 25 billion Euros allocated for the emergency, the government also focused on strengthening its distribution of intensive care equipment.(2)

\section{Clustering of cases in Lodi and Bergamo and adjusting for population size}

\section{Clustering of cases in specific areas}

There are large differences in population size of the provinces of Lodi and Bergamo, with the province of Lodi having a smaller population with respect to Bergamo. Although the provinces of Lodi and Bergamo have different population sizes, the areas where the cluster of outbreaks occurred were roughly comparable in size.(2) Unfortunately, there is no public data about the daily increase in the number of cases and deaths by municipality. We only have official data for one day (when the Lombardy region inadvertently published them online) and press data for another point in time. Data retrieved from the local press.(8) show that as of 29 February, out of 17 deaths occurring in the whole Lombardy, 6 occurred within the most affected municipalities within the province of Bergamo. Using daily data published by the local press on March 6,(9) we can conclude that the four most affected municipalities in Bergamo were: Albino (20 cases ), Alzano (32 cases), Nembro (74 cases), and Zogno (27 cases). Together those municipalities have 52,091 inhabitants. The same day, the number of positive cases in the overall Province of Bergamo was 623. The province of Bergamo consists of $1,114,590$ inhabitants. We can therefore see that $4.7 \%$ of the population accounted for $25 \%$ of the total number of cases. Evidence of this clustering has been shown by a detailed geographical analysis of the outbreak of symptomatic cases, which at the end of February were concentrated in Codogno (within the province of Lodi) and in Val Seriana (within the province of Bergamo).(2)

Using the data inadvertently released by Lombardy on Friday March 13, we can compare the Lodi cluster (the red zone of the 10 municipalities that was locked down since February the 24) with the one in Bergamo. On that day the total number of positive cases in the 10 municipalities in Lodi within the so-called "Red zone," amounted to 615 out of 1121 positive cases in the province (54\%). The 10 municipalities in the Lodi province account for $15 \%$ of the total population of the province itself (which in total is 230,198 inhabitants). The effect of early containment that we find in the main text is even more astounding, since it was only a very small portion of Lodi of 10 municipalities that make up $15 \%$ of the population which were isolated early. On the same day, the total number of positive cases in the comparable Bergamo "cluster" was 380 out of 2,145 in the province of Bergamo (18\%). Thus, once again, $4.7 \%$ of the population 
accounted for $18 \%$ of the total number of cases. As others who have focused on the detailed, geographic clustering at a more granular level in Lombardy,(2) we note that the cases emanated within a few municipalities. However, since these municipalities were not strictly closed, the virus spread to other municipalities within the province.

Adjusting number of daily cases by the size of the population

One concern is that the effect we see reflects the large differences in the population size of Lodi $(230,198)$ versus Bergamo $(1,114,590)$. Whilst population standardization is generally always an appropriate sensitivity analysis, a focus on cases per capita in the case of this outbreak would obscure evaluation of the effectiveness of the presence or absence of a "lockdown" which by design is meant to confine transmission within the areas of early outbreak.

As elaborated above, we purposefully choose to focus on the absolute daily case numbers due to the clustering of cases amongst comparably sized clusters of the municipalities in Lodi and Bergamo during the early stages of the spread. Adjusting for overall population size at such low levels of case numbers would obscure the important dynamics of understanding this early spread. For additional sensitivity analyses to complement Figure 2 in the main text, here we present extra figures that account for the larger population size of the province of Bergamo. (Fig S4-S5). Figure 44 shows the log number of positive COVID-19 cases by day, reflecting percentage rather than absolute increases. Figure $\mathrm{S}_{5}$ shows the same for log cases per 10,000 of the population by day. These figures both confirm a flatter trajectory of growth in cases in the province of Lodi compared to the province of Bergamo. These transformations tell a similar story to Figure 2, since we are using the slope to extrapolate that these outcomes become dramatically worse over time.

\section{$\underline{\text { References }}$}

1. European Commission, Lombardy. Intern. Mark. Ind. Entrep. SMEs (2020), (available at https://ec.europa.eu/growth/tools-databases/regional-innovation-monitor/baseprofile/lombardy).

2. C. D et al., The early phase of the COVID-19 outbreak in Lombardy, Italy. arXiv (2020) (available at http://arxiv.org/abs/2003.09320).

3. F. Gastaldi, Coronavirus: fugge da Codogno, trovato a Firenze. Altri 5 in fuga dalle «zone rosse». Corr. Della Sera (2020), (available at https://www.corriere.it/cronache/20_febbraio_27/coronavirus-fugge-codogno-trovatofirenze-altri-5-fuga-zone-rosse-871f3486-592c-11ea-af71899699a3d6d8.shtml?refresh_ce-cp).

4. M. Imarisio, Coronavirus, Fabiano Di Marco: «Atalanta-Valencia è stata una bomba biologica». Corr. Della Sera (2020), (available at 
https://www.corriere.it/cronache/20_marzo_20/primi-casi-23-febbraiooggi-usiamoogni-minuto860o-litri-ossigeno-a5c20c2e-6aed-11ea-b40a-2e7c2eee59c6.shtml).

5. C. Baldi, La Bergamasca potrebbe diventare una nuova zona rossa. Vie deserte, negozi sbarrati e paura: "Viviamo da rintanati senza uscire." La Stamp. (2020).

6. A. Carli, Coronavirus: chiusa la Lombardia e 14 province, 16,7 milioni di persone coinvolte. Cosa prevede il decreto. 24 Ital. (2020), (available at coronavirus: chiusa la Lombardia e 14 province, 16,7 milioni di persone coinvolte. Cosa prevede il decreto).

7. fanpage.it, Coronavirus: chi è Domenico Arcuri, il commissario delegato per l'emergenza scelto da Conte. fangpage.it (2020), (available at coronavirus: chi è Domenico Arcuri, il commissario delegato per l'emergenza scelto da Conte\%oA\%oAcontinua su:

https://www.fanpage.it/attualita/coronavirus-il-governo-nominera-domenico-arcuricommissario-delegato-per-lemergenza/\%oAhttps://www.fanpage.it/).

8. Editorial, Coronavirus, le vittime salgono a sette I contagi in Bergamasca sono 103. L'Eco di Bergamo (2020), (available at https://www.ecodibergamo.it/stories/bergamocitta/coronavirus-le-vittime-salgono-a-settei-contagi-in-bergamasca-sono103_1342996_11/).

9. Editors BergamoNews, Coronavirus: in Bergamasca 623 contagiati, 43 i decessi. Bergamo News Online (2020), (available at https://www.bergamonews.it/2020/03/o7/coronavirus-in-bergamasca-623-contagiati43-i-decessi/358382/). 
Fig. S1. A timeline of public and government health COVID-19 interventions and daily number of cases and deaths, Lodi, Bergamo and Italy, February 21 to March 22, 2020

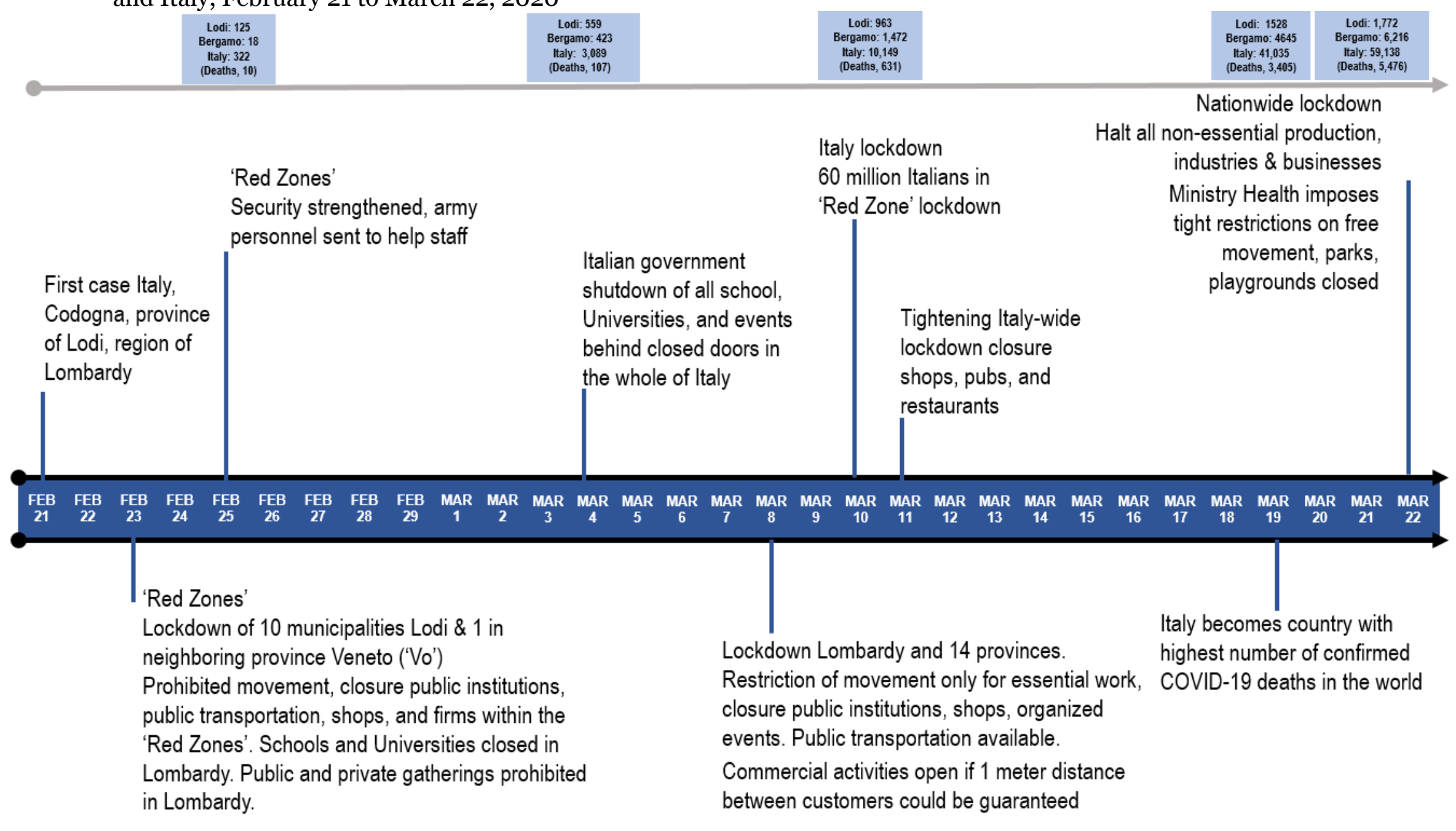




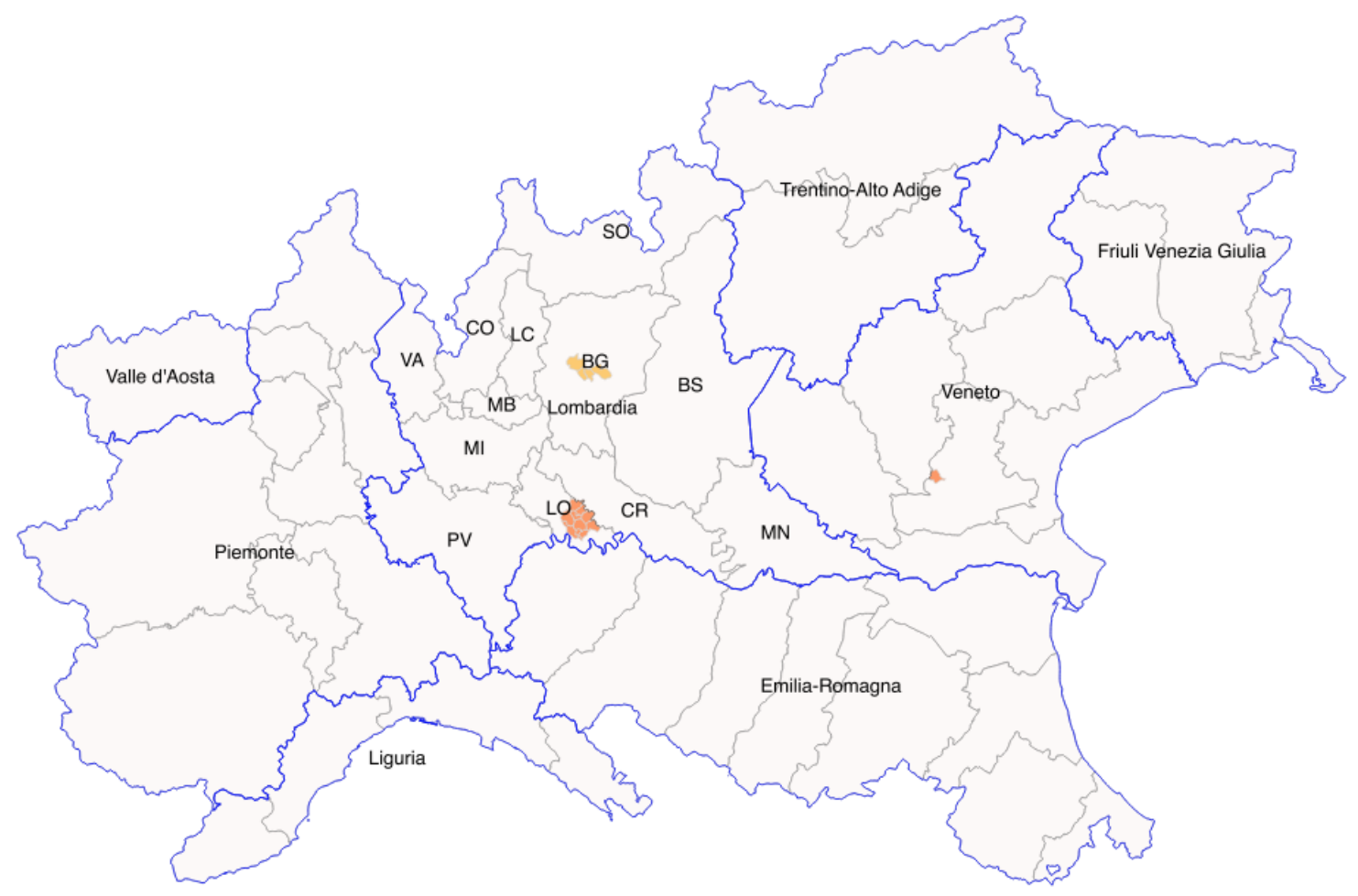

Fig. S2. The two "Red zones" for COVID-19 (as of February 25 2020) and the cluster of Albino, Alzano, Nembro, and Zogno in Bergamo, Northern Italy 


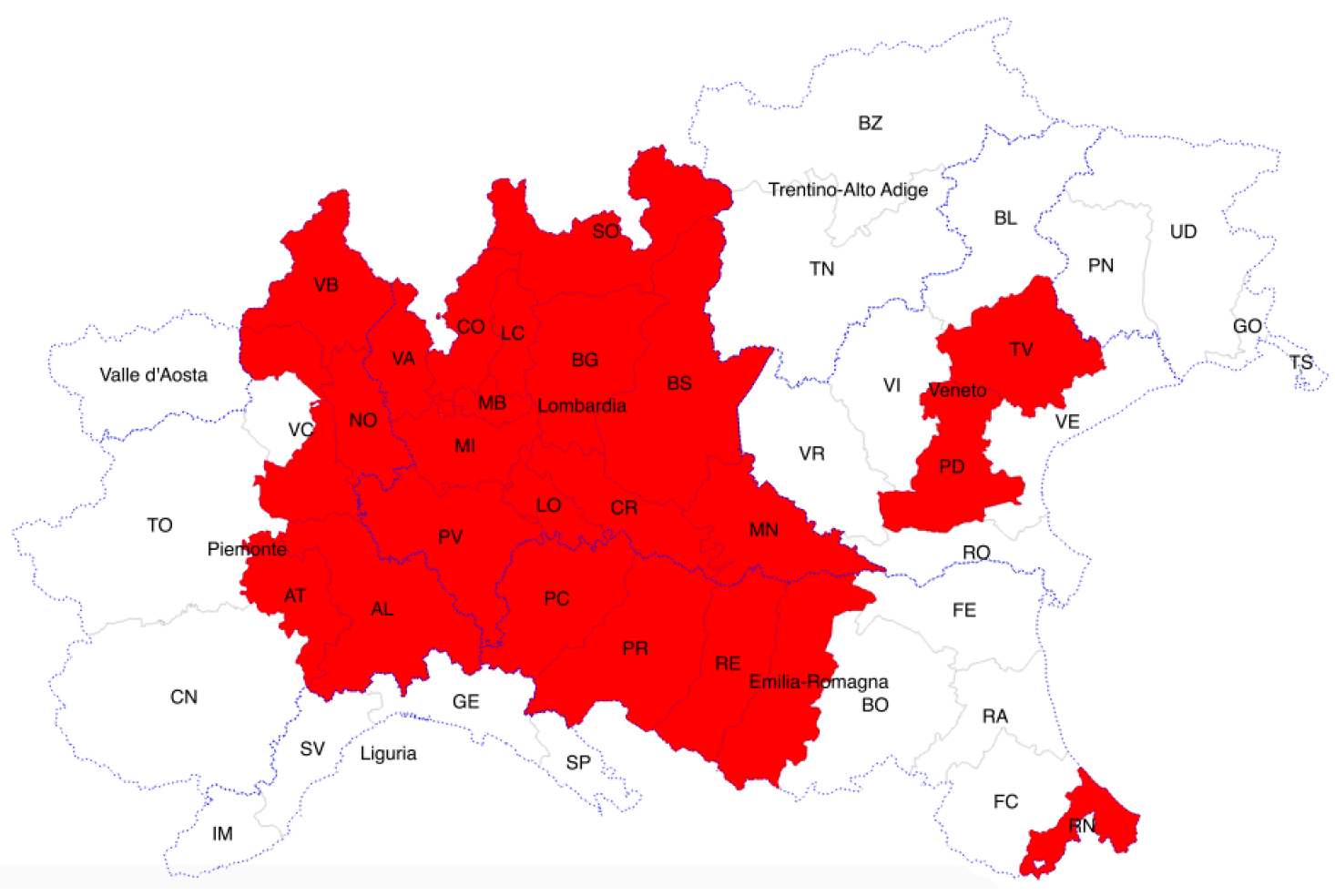

Fig. S3. Lockdown provinces in Northern Italy as of March 8, 2020. Note: The province of PesaroUrbino is not shown here. It is located in the center of Italy, within the region of Marche. 


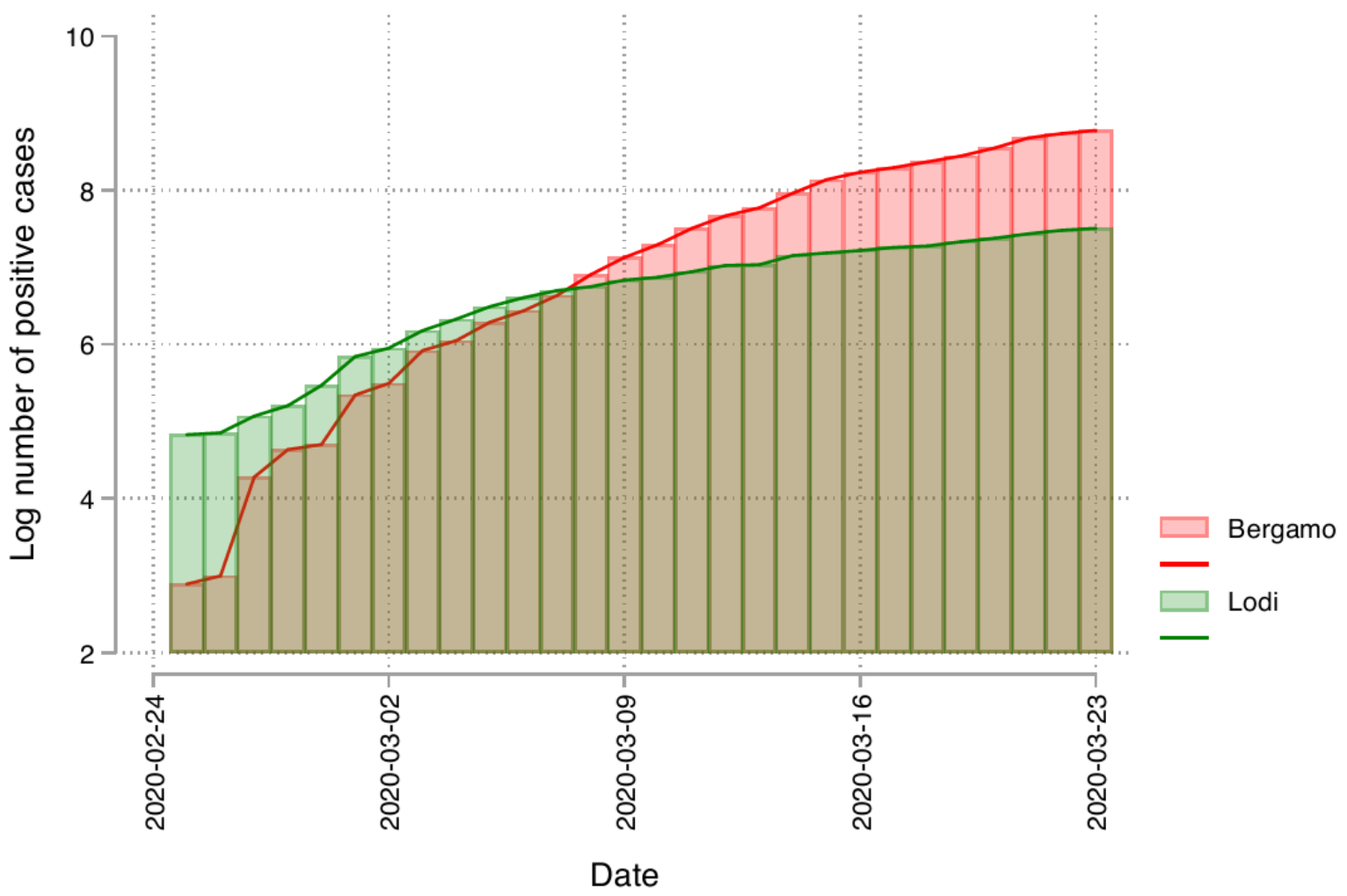

Fig. S4. Log of total daily COVID-19, February 24-March 23, 2020, Province of Lodi and Bergamo Notes: Green represents Lodi and Red Bergamo. 


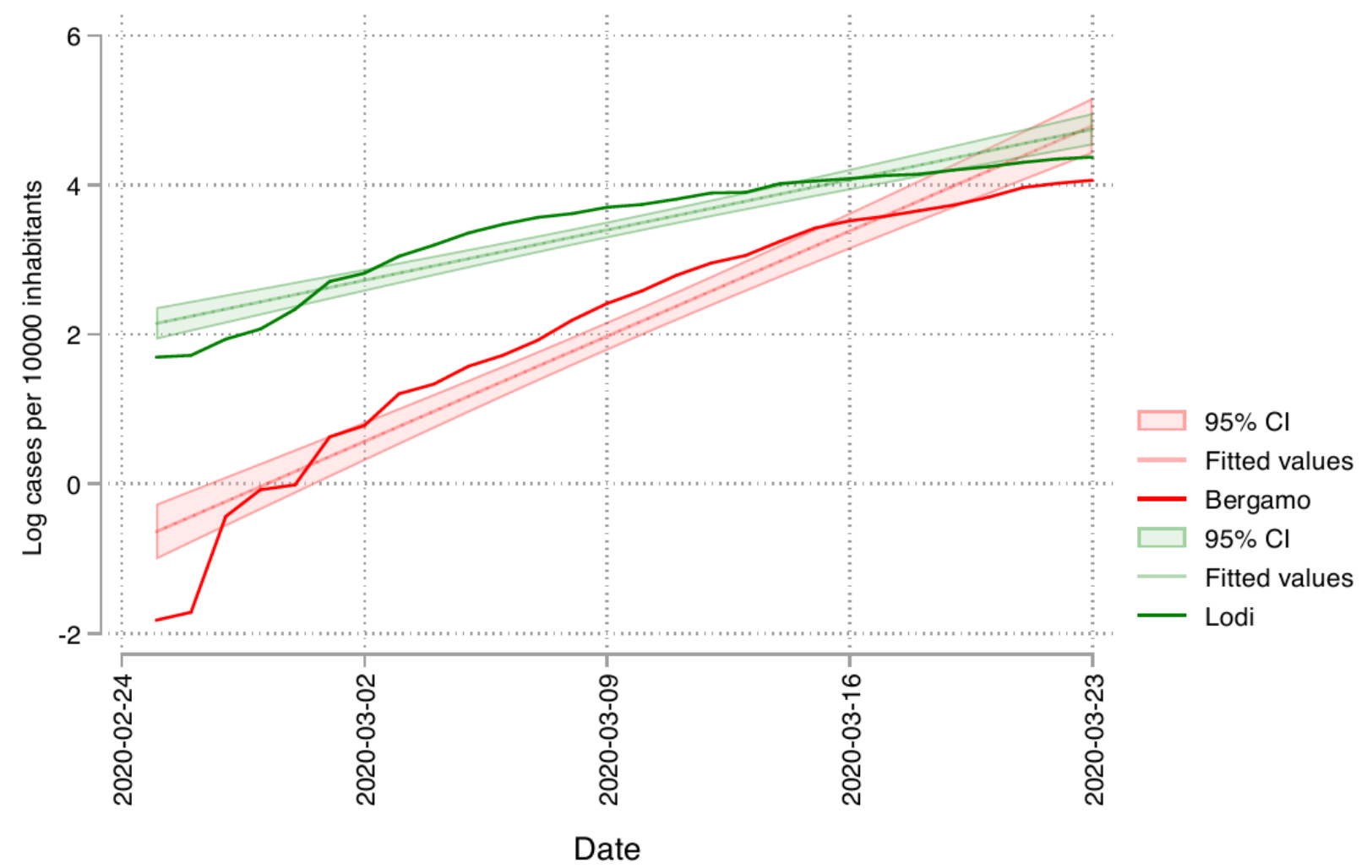

Fig. S5. Log of total COVID-19 cases per 10,000 inhabitants, February 24-March 23, 2020, Province of Lodi and Bergamo. Note: Green represents Lodi and Red Bergamo. Solid lines represent the log total of cases per 10,000 inhabitants in each province. The line represents a linear fit with with $95 \%$ confidence intervals (CIs). 